\title{
EUTANÁSIA: MORTE (IN)DIGNA PARA ANIMAIS NÃO HUMANOS ?
}

Mery Chalfun ${ }^{1}$

\section{RESUMO:}

A pesquisa se propõe a analisar se a eutanásia realizada em animais possui a mesma finalidade que possui em humanos, ou seja, se ocorre como forma de morte digna ou apenas como um procedimento econômico e de interesse humano. Se o procedimento regulamentado pelo Conselho Federal de Medicina Veterinária (CFMV) e demais órgãos está em consonância com os princípios e doutrina defendida na área Direito dos Animais. Destaca, ainda, a necessidade de tratamentos e possibilidades que se ajustem a padrões de ética animal, de acordo com a regulação dos órgãos responsáveis por regulamentar o atuar do médico veterinário e procedimento.

Palavras-chave: Direito dos Animais; eutanásia; regulação; dignidade.

\section{EUTHANASIA: (IN) DIGNITY DEATH FOR NON-HUMAN ANIMALS?}

\begin{abstract}
:
The research aims to analyze whether euthanasia performed on animals has the same purpose as it does on humans, that is, if it occurs as a form of dignified death or just as an economic procedure and of human interest. If the procedure regulated by the Federal Council of Veterinary Medicine (CFMV) and other bodies is in line with the principles and doctrine defended in the area of Animal Law. It also highlights the need for treatments and possibilities that adjust to animal ethical standards, according to the regulation of the bodies responsible for regulating the veterinarian's performance and procedure.
\end{abstract}

Keywords: Animal law; euthanasia; regulation, dignity

\section{Introdução:}

A problemática investigada e que se estuda neste trabalho é a de verificar se o procedimento da eutanásia e regulamentado pelo Conselho Federal de Medicina Veterinária, Conama e Concea está ou não em conformidade com a nova disciplina jurídica em formação, Direito dos Animais.

Eutanásia pressupõe a morte digna com a finalidade de por fim ao sofrimento e não prolongar uma vida repleta de sofrimento ou com doença incurável que em algum momento se

\footnotetext{
${ }^{1}$ Doutora em Direito pela UVA-RJ. Mestre em Direito pela UNESA. Graduação em Direito pela PUC-RJ. Professora, coordenadora adjunta do curso de Direito (Tijuca) e pesquisadora da Universidade Veiga de Almeida. Membro da Comissão de Bioética (OAB\RJ), grupo MUDA (Mulheres Pesquisadoras do Direito Animal), Instituto Abolicionista Animal. Parecerista da Revista Brasileira de Direito Animal, Asociación Latinoamericana de Derecho Animal (ALDA), Participação como pesquisadora convidada no grupo de pesquisa Centro de Ética Ambiental (UFRJ). . E-mail: merychalfun@hotmail.com
} 
torna insuportável. No que tange ao Direito dos Animais, a eutanásia não tem se verificado em regra no sentido de proporcionar dignidade ao animal, morte digna ou liberdade para um sofrimento, uma vez que a prática nem sempre é bem utilizada.

Estudada no âmbito da Bioética ${ }^{2}$, disciplina com intuito de proporcionar ética da vida na esfera médica e ciência, indica princípios nas diversas esferas médicas, em regra para seres humanos, no entanto hoje passa a envolver também animais e meio ambiente.

Visando regulamentar as questões abordadas na esfera da bioética forma-se o biodireito, normatizando as questões surgidas com os avanços da biomedicina e preservando a dignidade da vida e direitos fundamentais.

Em paralelo, nasce o direito dos animais, incluindo os nas esferas de consideração e como titulares de direitos fundamentais, como vida, liberdade e integridade física e psíquica, conferindo-lhes dignidade. Há o reconhecimento da senciência animal e questionamento quanto às formas de utilização dos animais e procedimentos aos quais são submetidos. Assim, ainda que de forma embrionária, os cuidados com a saúde, vida e morte digna dos animais começa a ser considerado também na bioética e biodireito em conjunto com o direito dos animais ou direto animal $^{3}$.

O objetivo do trabalho é observar se há conflito ético e normativo, diante da possibilidade de tratamento ou inexistência de doença nos animais, sendo aplicada a eutanásia apenas por ser opção mais econômica e cômoda na solução de um problema ou "inconveniente" de cuidar do animal enfermo, gerando, na verdade o que se convencionou chamar de sacrifício do animal e não propriamente a chamada eutanásia, vista como ultima ratio, ou seja, quando não existem chances de cura da doença do animal.

Como objetivos específicos destacam-se os de (i) modular uma regulamentação segura para se estabelecer critérios norteadores da eutanásia animal; (ii) verificar a utilização inadequada do instituto em comento e a responsabilidade dos donos dos animais eutanasiados e a responsabilidade civil do médico veterinário; (iii) observar os motivos pelos quais os responsáveis pelos animais autorizam a eutanásia dos animais; (iv) examinar se a eutanásia em animais reflete os preceitos sustentados na doutrina direito dos animais.

\footnotetext{
${ }^{2}$ A expressão bioética se consolidou a partir de obras como "The Science of survival" (1970) e "Bioethics: a bridge to the future" (1971), do oncologista americano Van Ressenlaer Potter.

${ }^{3}$ A expressão; Direito Animal (ramo autônomo) e Direito dos Animais (Direitos fundamentais) é adotada de forma diferenciada por alguns autores. No presente trabalho não se pretende aprofundar o debate.
} 
A abordagem metodológica da pesquisa utilizada é a revisão literária integrada e interdisciplinar nas searas do Direito, da regulamentação pelos órgãos públicos, e, ainda, o estudo de casos.

\section{Eutanásia:}

Eutanásia pressupõe a morte digna ou boa morte, com intuito de por fim ao sofrimento e não prolongar uma vida repleta de sofrimento ou com doença incurável que em algum momento alcançará uma sobrevivência complexa.

Derivado do grego ê̂ (bom) e thánatos (morte), significa boa morte ou morte sem sofrimento. Ao tratar de seres humanos a eutanásia aborda o princípio da autonomia do paciente e de sua família, a relação com o profissional da saúde e sociedade, proporcionando o fim da vida como algo que reflete o corolário de vida digna, ou seja, se não é possível proporcionar uma vida com respeito, livre de sofrimento longo e lento, de tratamento desumano e repleto de dor, talvez a opção pela morte seja o caminho possível.

Ao que se indica, a expressão foi utilizada pela primeira vez ao descrever a morte do imperador Augusto, conforme relatado pelo historiador latino Suetônio, século II d.C: “A morte que o destino lhe concedeu foi suave, tal qual sempre desejara: pois todas as vezes que ouvia dizer que alguém morrera rápido e sem dor, desejava para si e para os seus igual eutanásia (conforme a palavra que costumava empregar)" (SUETÔNIO, 2002, p.97).

Passados alguns séculos, em 1623, Francis Bacon defendeu a eutanásia como a forma adequada para doenças tidas como incuráveis. Abordou em sua obra Historia vitae et mortis a expressão eutanásia de forma mais próxima ao que se sustenta atualmente, ou seja, aquela praticada por médicos quando não há cura para determinada doença, como forma de acabar com a dor e o sofrimento. A morte, nesses casos, é mais calma e mais tranquila. Foi, porém, somente no século XVII, com Roger Bacon e Tomás Morus, que a expressão ganhou efetivo significado de pôr fim ao paciente terminal em sofrimento (JIMÉNEZ DE ASÚA, 1992).

Atualmente, ao tratar de seres humanos, a eutanásia aborda o princípio da autonomia do paciente e de sua família, a relação com o profissional da saúde e sociedade, proporcionando o fim da vida como algo que reflete o corolário de vida digna. Conforme aborda Ron Leifer (1997, p.96):

Evidentemente, o desejo de morte é o oposto do desejo de vida. Assim como o desejo de vida se baseia no desejo de prazer e felicidade, o desejo de morte se baseia no desejo de escapar à dor e ao mal. Não há dúvida de que as pessoas doentes e às portas da 
morte, quando cometem suicídio, são motivadas pelo desejo de escapar à dor e ao sofrimento físico.

Busca-se a eutanásia em suas diversas modalidades como forma de não sentir dor ou para que se tenha dignidade no fim de uma vida, vida essa incapaz de ser o que já se foi outrora.

Apesar de não existir o tipo penal específico eutanásia, sua prática será considerada como homicídio simples e o médico em princípio não deve realizá-la. Ao praticar a eutanásia, poderá haver aplicação do artigo 121, parágrafo $1^{\circ}$ (homicídio privilegiadolcompaixão), artigo 122 (auxílio ao suicídio) ou artigo 135 (omissão de socorro) do Código Penal atual. No entanto, defende-se a autonomia do paciente que sinaliza quanto à intenção de pôr fim a vida em determinadas situações.

Conforme Resolução 1995 de 2012 do CFM (Conselho Federal de Medicina), é possível dispor de vontade ou diretrizes quanto à eutanásia no caso de futura impossibilidade de manifestar vontade ou tratamento. O documento com tal manifestação passou a ser chamado testamento vital e, apesar de ainda não ser abordado no âmbito legislativo do Direito Civil, é uma realidade na esfera médica e na doutrina. A eutanásia é regulamentada em alguns países, como por exemplo; Holanda e Suíça.

\subsection{Eutanásia em Animais}

A partir da resolução n 322 de 1981, é elaborado pelo Conselho Federal de Medicina Veterinária o primeiro Código de Ética da Medicina Veterinária, já que a resolução $\mathrm{n}^{\circ} 23$ de 1969 não trazia grandes novidades.

Com a resolução $n^{\circ} 722$ de 2002, questões éticas e de responsabilidade ganham maior destaque e regulamentação. Até mesmo o juramento do médico-veterinário ganha novo contorno. $\mathrm{O}$ artigo $4^{\circ}$ do Código estabelece os procedimentos humanitários cujo foco é evitar dor e sofrimento.

Desperta-se nesse momento, para um novo formato de responsabilidade, ou seja, não mais preocupado apenas com qualidade de produtos de origem animal, com a erradicação de doenças e com a saúde pública e ambiental, mas também com tratamentos mais éticos, com o bem-estar do animal e com a responsabilidade do médico-veterinário no desenvolvimento de suas atividades, que vai ganhar impulso com a resolução $n^{\circ} 1138$ de 2016, que estabelece sobre o bem-estar animal e o animal como paciente. 
Quanto à eutanásia especificamente, o CFMV (Conselho Federal de Medicina Veterinária), órgão responsável por regulamentar à atividade do médico veterinário, permite por intermédio da Resolução 1138 de 2016, o procedimento nos casos devidamente justificados, observando princípios básicos de saúde pública, legislação de proteção aos animais e normas do CFMV (artigo $6^{\circ}, \mathrm{XIII}$ ); respeitando as necessidades fisiológicas, etológicas e ecológicas dos animais, não atentando contra suas funções vitais e impedindo que outros o façam (artigo 18, II).

A Comissão de Ética, Bioética e Bem-estar Animal do CFMV (2012, p.15-16) elaborou ainda um guia de Boas Práticas de Eutanásia em Animais, prevendo conceitos e procedimentos recomendados:

\begin{abstract}
Dentro deste contexto, a eutanásia deve ser indicada quando: 1. o bem-estar do animal estiver comprometido de forma irreversível, sendo um meio de eliminar a dor e/ou o sofrimento dos animais, os quais não podem ser controlados por meio de analgésicos, sedativos ou de outros tratamentos; 2. o animal constituir ameaça à saúde pública; 3. o animal constituir risco à fauna nativa ou ao meio ambiente; 4 . o animal for objeto de ensino ou pesquisa; 5. o tratamento representar custos incompatíveis com a atividade produtiva a que o animal se destina ou com os recursos financeiros do proprietário.

No âmbito das indicações acima descritas, é importante ressaltar que a utilização da eutanásia em animais fica restrita às situações nas quais não há a possibilidade da adoção de medidas alternativas. Além disso, deve-se atentar para o respeito às legislações pertinentes."
\end{abstract}

Observa-se que a regulamentação visa o animal em primeiro momento, mas outros pontos são considerados, pois permite a utilização em pesquisa e morte após utilização, além de considerar o meio ambiente e o custo.

Na verdade a eutanásia de animais se dá por diversos motivos, tais como: zoonoses (mesmo quando haja tratamento), após experimentações científicas (mortos e descartados), idade avançada, vontade do “dono”. Observa-se, portanto, que nem sempre a eutanásia será realizada em benefício do animal.

As formas de "eutanásia" são previstas pelo CFMV e também pelo CONCEA (Conselho Nacional de Controle de Experimentação Animal) e CONAMA (Conselho Nacional de Meio Ambiente). No âmbito das pesquisas é comum que os animais sejam mortos ao final, ainda que estejam sadios, pois não devem ser utilizados repetidas vezes e consideram risco para o meio ambiente.

A Lei $n^{\circ} 11.794$ de 2008 prevê em seu artigo 14, parágrafo $1^{\circ}$ este procedimento, e as formas de eutanásia estão previstas nos manuais e pelo CONAMA. 
A resolução normativa $n^{\circ} 37$ de 15 de fevereiro de 2018 e o anexo da resolução do Conselho Nacional de Controle de Experimentação Animal (CONCEA) baixa as diretrizes quanto aos procedimentos de eutanásia realizados em animais nas atividades de ensino e pesquisa. Nessas diretrizes, é possível verificar as condições, características e os efeitos da forma de eutanásia (hipóxia, depressão neuronal e/ou interrupção da atividade cerebral e destruição de neurônios vitais). Estipula ainda sobre o executor e as condições de bem-estar para o animal; e sobre os métodos, que devem ser rápidos e não gerar dor ou estresse. No entanto, ao realizar a leitura atenta do texto, observa-se que nem sempre os objetivos podem ser atendidos. ${ }^{4}$

A eutanásia deve seguir procedimento que induza inconsciência e, em seguida, morte, sem qualquer evidência de dor, sofrimento ou agonia para o animal, longe dos outros animais e por profissional treinado. Conforme Resolução Normativa $\mathrm{n}^{\circ} 6$ de 10 de julho de 2012 e resolução $\mathrm{n}^{\circ} 37$ e seu anexo de 2018, os procedimentos devem ser supervisionados por um responsável médico-veterinário.

Os métodos são classificados como "recomendados", "aceitos com restrições" ou "inaceitáveis", além de considerar a espécie e tamanho. Entre os métodos listados, citam-se alguns: dióxido de carbono $\left(\mathrm{CO}_{2}\right)$ : método não recomendado para nenhuma espécie, pois seu aspecto humanitário é questionável, sendo aceito com restrições; deslocamento cervical: poucos estudos confirmam tratar-se de método humanitário; decapitação: todos os animais deveriam ser anestesiados, no entanto, para evitar interferência nos resultados da pesquisa, nem sempre o são. Há controvérsia quanto ao fato de ser humanitário.

Todos os métodos possuem restrições, podendo ser citados, ainda, pistolas pneumáticas, armas de fogo, micro-ondas, armadilhas, compressão torácica etc.

Cada instituição tem liberdade para estabelecer em âmbito interno a forma que será adotada como "eutanásia" desde que siga seu comité de ética (CEUA- comité de ética no uso de animais), resoluções e os padrões do CONCEA.

Ocorre que a chamada "eutanásia" em animais pode ser apontada em muitos casos como verdadeiro extermínio ${ }^{5}$, pois nem sempre tem como intuito o benefício do animal. Conforme a filósofa Sônia Felipe:

\footnotetext{
${ }^{4}$ Recomenda-se a leitura completa da resolução e anexo: CONCEA. Resolução Normativa no 37 . Diretriz da prática de eutanásia do CONCEA. Disponível em: https://www.mctic.gov.br/mctic/export/sites/institucional /institucional/concea/arquivos/legislacao/resolucoes_normativas/Resolucao-Normativa-n-37-Diretriz-da-Pratica-deEutanasia_site-concea.pdf.

${ }^{5} \mathrm{Na}$ Rússia é comum a existência de animais nas ruas em decorrência da falta de esterilização. Foi noticiado a "eutanásia” destes animais como forma de "melhorar “ a imagem do país. Mais informações Disponível em
} 
Matar um animal em estado natural de agonia física ou sofrimento, quando tal estado é causado por eventos naturais, ambientais ou biológicos, tais como os processos degenerativos e irreversíveis do envelhecimento, ou outras anomalias para as quais não há cura, com a finalidade de propiciar alívio, quando a dor ou sofrimento não podem cessar a não ser fazendo-se cessar toda a atividade mental, tirar-lhe então, a vida, de modo indolor, seria eutanásia (...). Quaisquer outras formas de execução de animais devem ser vistas, pura e simplesmente, como extermínio (...). Interesses alheios estão por detrás dessas execuções, não interesse dos próprios animais (2007.p. 83)

\subsubsection{Zoonoses}

O controle de zoonoses em muitas vezes ocorre através da eutanásia. Tendo como argumento o artigo $2^{\circ}$, parágrafo $1^{\circ}$ da Lei 8080190 (Lei orgânica da saúde) que tem por intuito a diminuição dos riscos de doença, e informe técnico da OMS de $1973^{6}$ (não mais recomendado) animais são recolhidos das ruas e sacrificados ainda que sadios, pelo simples fato de serem considerados possíveis vetores. O instituto Pasteur e o Ministério da Saúde recomendavam a "eutanásia" em locais endêmicos, ainda que os animais não estivessem contaminados, além disso, algumas doenças são tratáveis e controláveis ${ }^{7}$.

Até 1995 pesquisas indicam que somente nos EUA foram mortos em torno de 18 milhões de cães, além de um gasto de 1 bilhão de dólares por ano com as mortes. No município de São Paulo em torno de 25 a 30 mil cães foram mortos entre 1997 a 2002. Em 2012 somente no primeiro semestre 912 cães e 103 gatos foram mortos no CCZ de São Paulo (SOTO, 2010).

No entanto, polêmicas surgem quanto à eficácia da eutanásia e consequências para não humanos e humanos, destacando três problemas principais: não é eficaz no controle populacional ou de doença; desgaste psicológico para os funcionários que realizam a eutanásia e riscos de contaminação; os métodos utilizados nem sempre são adequados. (SOTO, 2010)

\footnotetext{
https://brasil.elpais.com/brasil/2018/01/12/internacional/1515767153_639143.html Rússia (citar o caso de morte dos animais na rua) > Acesso em 26.06.2018

${ }^{6}$ No $6^{\circ}$ manual técnico do instituto Pasteur, recomendava-se a eutanásia: "a eutanásia é aplicada em animais aparentemente sadios ou a outros considerados indesejados, como é frequente nos serviços dirigidos ao controle de população de animais". Ministério da saúde: em áreas endêmicas para raiva devem ser recolhidos "anualmente $20 \%$ da população canina estimada aos canis públicos, onde devem permanecer por prazo não superior a 72 horas para serem resgatados por seus donos. Passado esse prazo, serão doados às instituições de ensino biomédico ou sacrificados". (SECRETARIA DO ESTADO DE SÃO PAULO. Manual técnico do Instituto Pasteur. Disponível em http://www.saude.sp.gov.br/resources/instituto-pasteur/pdf/manuais/manual_06.pdf. Acesso em 10.11.2019)

${ }^{7}$ Exemplo é a Leishmaniose, que sempre teve como solução prioritária a "eutanásia", no entanto, trata-se de doença tratável, apesar de incurável, além de formas preventivas da doença, como vacina e coleiras com inseticida. Atualmente o projeto 1738/11 foi aprovado pela comissão de seguridade social e família que prevê vacina obrigatória e anual de forma gratuita, assim como ocorre com a raiva.

Para aprofundar o tema ler o artigo Direito dos Animais e o controle da Leishmaniose: Novas Perspectivas. Revista de Biodireito e Direito dos Animais. V.4. n.1 2018. Disponível em https://indexlaw.org/index.php/revistarbda/article/view/4224
} 
Atualmente existem programas de educação, vacinação ${ }^{8}$ e esterilização em medidas preventivas e em conformidade com os informes atuais da Organização Mundial de Saúde, até porque o informe técnico $8^{\circ}$ da OMS de 1998 e pesquisa realizada pela World Health Organization (WHO), entre 1981 e 1988 admitiu a ineficácia da eutanásia como forma de controle de doenças em cães e gatos. Não obstante alguns países seguem com a prática de eutanásia

\subsubsection{Meio ambiente e animais exóticos}

Animais exóticos são aqueles que não fazem parte da fauna nacional, sendo inseridos ou que ingressam em território nacional. Alguns estão na natureza (saguis, javalis, mosquito aedes aegypti), enquanto outros são retirados de seus habitats para serem utilizados em entretenimento humano, zoológicos ou circos, como leões, zebras, elefantes, ursos, crocodilos.

Algumas formas de controle são determinadas pelo Ibama e geram questionamentos, como no caso do Javali, autorizada a caça como forma de controle através da instrução normativa $n^{\circ} 03 / 2013$.

Nos zoológicos há uma pressão para que sejam mantidas as mais diversas espécies possíveis, sendo comum a realização de eutanásia em animais saudáveis. Assim alguns filhotes considerados "desnecessários" são mortos na chamada "eutanásia", como ocorrido em 2012 no zoológico de Copenhague no qual dois filhotes de leopardo foram mortos por injeção letal, pois já existia população suficiente da espécie no local ${ }^{9}$.

Outro caso ocorreu no Rio Grande do Sul, o Ibama em conjunto com o Ministério Público Federal e Secretária Estadual da Agricultura determinou em 2017 o sacrifício (“eutanásia”) de cerca 300 cervos exóticos que viviam no parque Pampas Safari, tendo como justificativa um surto de tuberculose. Foi determinada a morte de todos os animais, no entanto,

\footnotetext{
8 "A cinomose, doença de alto risco que atinge principalmente cães filhotes, agora tem uma opção de cura mais eficaz. Uma cirurgia inédita com o uso de células-tronco promete eliminar o vírus causador da cinomose em menos de dois dias. No Recife, um cão de rua de 4 meses resgatado por um casal foi diagnosticado com o vírus. Depois de ser considerada até a possibilidade de eutanásia por médicos, devido ao alto grau de debilidade do cão, o veterinário Magno José Gonçalves apresentou uma cirurgia inédita com o uso de células-tronco [...] Para Mel Sobral, que adotou o cão, a escolha de tentar o novo procedimento foi acertada: 'Não entrava na minha cabeça devolver o cão para rua ou eutanasiar sem tentar tudo', disse, emocionada. A cinomose, doença com a qual Malta foi diagnosticado pode atingir vários órgãos, inclusive com chances de atuar em todo o organismo. A cinomose é causada por um vírus muito resistente a ambientes secos e frios, sendo sensível ao calor e luz solar, por exemplo. A doença pode causar o óbito dos animais filhotes, mas os adultos, caso não estejam vacinados, também podem se contaminar". (CIRURGIA inédita salva cachorro de rua resgatado com cinomose. Olhar animal. Disponível em http://olhar animal.org/cirurgia-inedita-salva-cachorro-de-rua-resgatado-com-cinomose/. Acesso em 15\12 \2018).

${ }^{9}$ ZOOLÓGICOS adotam métodos de eutanásia para controlar crescimento de espécies. CFMV. Disponível em <http://www.cfmv.gov.br/portal/noticia.php?cod=3088> Acesso em 10.11.2019.
} 
nem todos estavam contaminados. A forma considerada para "eutanásia” e abate humanitário se deu através de pistola pneumática ${ }^{10}$.

Ocorreram protestos e medidas judiciais para evitar a morte dos animais, como por exemplo, através da ex secretária municipal dos Direitos humanos de Porto Alegre, que entendeu pela possibilidade de tratamento e desconsideração quanto a vida animal com a medida em massa.

\subsubsection{Experimentação científica.}

A experimentação científica também é um fator. Nos laboratórios e nas salas de aula, animais são utilizados em diversos experimentos: cães em cirurgias; ratos para verificação de sistema imunológico, macacos em análise de comportamento, porcos para pesquisa de cicatrização, cavalos em sorologia, gato em experimentos cerebrais, coelhos em experimentos oculares e cutâneos, entre outros diversos experimentos e procedimentos com as mais diversas finalidades, como educação, produção de remédios, produção de cosméticos, análises comportamentais; armamentos, toxidade, cegueira, psicológicos. Além disso, são realizados a custo de muitas vidas experimentos em busca de aprendizado e conhecimento, para benefício do animal ou do ser humano.

Apesar de muitas instituições terem rompido com essa utilização, é certo que animais permanecem sendo utilizados em universidades e centros de pesquisa, na esfera da biomedicina, biologia, veterinária ${ }^{11}$.

A lei ${ }^{\circ} 11.994$ de 2008 estabelece diversos critérios e criação do CONCEA (Conselho Nacional de Controle de Experimentação Animal) e estabelecimento de CEUA (Comissões de ética) para todas as instituições que utilizam animais nas pesquisas.

$\mathrm{Na}$ esfera da bioética foram estabelecidos alguns princípios que devem nortear as pesquisas, conhecidos como 3 Rs, ou seja, Reduction (redução), Refinement (refinamento) e Replacement (substituição). Criados na década de 1950 e difundidos inicialmente através da obra

10 PREITE SOBRINHO, Wanderley. Por que 300 cervos exóticos estão sendo sacrificados no RS? Uol. Disponível em https://noticias.uol.com.br/meio-ambiente/ultimas-noticias/redacao/2017/08/23/ibama-determinasacrificio-de-300-cervos-em-area-de-parque-no-rs.htm.

Veja mais em: IBAMA determina sacrifício de 300 cervos na área de parque no Rio Grande do Sul. https://noticias.uol.com.br/meio-ambiente/ultimas-noticias/redacao/2017/08/23/ibama-determina-sacrificio-de-300cervos-em-area-de-parque-no-rs.htm?cmpid=copiaecola.

11 Experimentos são realizados com diversas finalidades: toxidade, cosméticos, saúde, testes psicológicos e comportamentais, queimadura, cegueira, entre outros. O livro Libertação Animal de Peter Singer e Jaulas Vazias de Tom Regan trazem relatos assustadores. 
"The principles of humane experimental tecnique" dos autores William Russell e Rex Burch, referências nesta doutrina, foram incorporados na legislação nacional e internacional que regulamenta experimentação com animais.

Os princípios são observados na Lei $\mathrm{n}^{\circ} 11.794$ de 2008, pois estabelece a redução do número de animais utilizados nas pesquisas e o refinamento que consiste na tentativa de melhorar as formas de estudos, visando proporcionar ao animal o mínimo possível de sofrimento. A substituição por outras formas também está presente, e é o princípio defendido na esfera do Direito dos Animais ${ }^{12}$.

$\mathrm{O}$ artigo 14 , parágrafo $3^{\circ}$ e $4^{\circ}$, por exemplo, determina que as pesquisas devem ser filmadas, registradas, fotografadas, de forma a não ser repetida desnecessariamente, pelo simples prazer, de se fazer de novo algo que já se tem os resultados, preceitua ainda a redução do número de animais e do tempo de experimento. Além disso, o artigo $5^{\circ}$ dispõe sobre a introdução de métodos que substituam a utilização de animais, assim como na Lei n ${ }^{\circ} 9.605$ de 1998 que aborda sobre crimes ambientais e dispõe sobre maus tratos em seu artigo 32, inclusive em experimentações.

Atualmente o Brasil conta com cerca de 17 métodos alternativos validados por meio da Resolução Normativa $n^{\circ} 18$, de 24 de setembro de 2014. Já a resolução normativa ${ }^{\circ} 31$ de 18 de agosto de 2016 do CONCEA reconhece 7 métodos alternativos agrupados em 4 grupos. Além disso, o instituto $1 \mathrm{R}$ vem desenvolvendo estudos no sentido de ampliar e consolidar somente novas possibilidades que substituam de forma definitiva o modelo animal.

Faltam incentivos a novos métodos e profissionais habilitados, portanto, animais permanecem sendo utilizados, e o que talvez fosse justificável no passado, atualmente é motivo de controvérsias, inclusive quanto à eutanásia realizada ao final dos procedimentos e estabelecidos nos manuais do CONAMA que consideram a melhor forma de interromper ou pôr fim aos experimentos com animais, ainda que ao final os animais estejam sadios, pois, em regra, não devem ser utilizados novamente, e consideram também a possibilidade de risco.

\footnotetext{
${ }^{12}$ Exemplo de substituição foi a produção da vacina contra a raiva. Para ser produzida essa vacina exigia-se a multiplicação do vírus no cérebro de camundongos recém-nascidos. Atualmente tal experimento é feito em células em cultura. Eliminando o uso de grandes quantidades de animais. Ademais, as culturas de tecidos, provenientes de biópsias, cordões umbilicais ou placentas descartadas, também dispensam o uso de animais. Em decorrência deste método de produção e a outros procedimentos, o Instituto Butantan reduziu em mais de $60 \%$ o uso de cobaias em testes. (ALTERNATIVES to animal testing. Revista Pesquisa Fapesp, junho, 2014. Disponível em https://lnbio.cnpem.br/alternatives/)
} 
Ao final os animais podem ser adotados se constatado ausência de qualquer risco de contaminação, mas em regra o que ocorre é a eutanásia que deve seguir procedimento que induza inconsciência e em seguida morte, sem qualquer evidência de dor, sofrimento ou agonia para o animal, longe dos outros animais e por profissional treinado.

A forma de eutanásia e procedimento adotado nas universidades é estabelecido no âmbito de cada instituição por resoluções e CEUA e seguindo os padrões do CONCEA. A USP, por exemplo, estabelece em seu manual como método químico a câmara de $\mathrm{CO}_{2}$, que deve ser apropriada em conformidade com o tamanho do animal e calibração. Como método físico são o deslocamento cervical ou decapitação por meio de guilhotina. Após a verificação da morte e que os sinais vitais cessaram, os animais (chamados de carcaças) são colocados em sacos brancos com símbolo de risco biológico para descarte.

Observa-se que apesar dos manuais estabelecerem procedimentos que não gerem sofrimento, também são previstos métodos que geram algum tipo de risco e possibilidade de sofrimento. ${ }^{13}$

Este indicativo vem sendo incorporado nas legislações e defendida por um grupo crescente, de forma que a utilização de animais em experimentação termine em definitivo. Algumas universidades, como por exemplo; UFF, UFBA, UFSC e UFRGS já romperam com a prática nas salas de aula, e projetos de lei restringem a utilização dos animais como no caso de cosméticos, ou fornecem formas alternativas aos alunos que se recusam a utilizar animais em sala de aula ${ }^{14}$.

\subsubsection{Opção do tutor}

No caso de animais que convivem em âmbito familiar com humanos, em regra, a eutanásia busca realmente acabar com o sofrimento do animal. Inúmeros casos demonstram a opção pela eutanásia como forma de morte digna para o animal, com luto e tristeza para seus

\footnotetext{
${ }^{13}$ Maiores detalhes quanto aos métodos verificar em Disponível em <http://www.mctic.gov.br/mctic/export/sites/institucional/institucional/concea/arquivos/legislacao/resolucoes_norm ativas/Resolucao-Normativa-CONCEA-n-13-de-20.09.2013-D.O.U.-de-26.09.2012-Secao-I-Pag.-5.pdf>

${ }^{14}$ Resolução 30\2016 (CONCEA) - Instituto 1R -O Conselho Nacional de Controle da Experimentação Animal (CONCEA), vinculado ao Ministério da Ciência, Tecnologia e Inovação (MCTI), publicou no dia 3 de Fevereirol2016 no Diário Oficial da União, a Diretriz Brasileira Para o Cuidado e a Utilização de Animais em Atividades de Ensino Ou de Pesquisa Científica - DBCA), oficializando a responsabilidade institucional da oferta de métodos alternativos para os alunos objetor de Consciência, e o desenvolvimento de uma ouvidoria institucional para os assuntos relativos ao uso de animais, incluindo o apoio aos alunos.
} 
tutores. Alguns projetos auxiliam, inclusive, a superar o luto, e enterros e cremações são realizados em cerimônias de despedida e de respeito.

O procedimento deve ser realizado de forma indolor, não sendo permitido o uso de CO ou CO2 ou câmaras de gás. Pode ocorrer uma dose alta de anestesia e, após medicação que cause parada respiratória, o animal perde a consciência e o procedimento é rápido. No entanto, existem muitos casos em que há possibilidade de tratamento e o tutor (“dono") prefere realizar a eutanásia. Nesses casos, o médico-veterinário não deve realizar o procedimento. A decisão deve ser em conjunto e para o bem do animal.

Assim, a análise do procedimento chamado eutanásia em animais de forma predominante demonstra que são poucos os casos de realização em interesse do animal, ou seja, para proporcionar fim do sofrimento e morte digna. Percebe-se uma regulamentação que possibilita procedimento de morte com intuito de proteção ambiental e humano, ou mesmo, sem qualquer justificativa, ou seja, por mera vontade do tutor, e, nesse aspecto, há que se considerar outra questão importante: a guarda responsável. ${ }^{15}$

Ademais, as formas de eutanásia regulamentada nas resoluções do CFMV, CONAMA e CONCEA nem sempre são seguras quanto à ausência de dor e sofrimento.

Na maioria das vezes, o que ocorre é o sacrifício do animal, e não a eutanásia. O médicoveterinário deve repensar tal procedimento, que só deve ser realizado quando em benefício do animal efetivamente.

\section{Direito dos Animais}

Em visão tradicional a natureza jurídica dos animais pode ser analisada sob dois aspectos, ou seja; (i) no direito ambiental como recurso natural, bem difuso importante para o equilíbrio do ecossistema, bem comum do povo tutelados pelo Estado e pela sociedade ${ }^{16}$. No âmbito do Direito Civil (ii) animais são coisas, propriedade que se destina ao benefício humano, conforme

\footnotetext{
15 O abandono de animais é uma das crueldades que ocorrem no dia a dia e que podem levar a diversas questões quanto ao animal (maus tratos e sofrimento) e ambiental. São comuns os casos concretos de animais encontrados com diversas doenças, cruzamentos a cada cio e um ciclo vicioso de aumento de animais abandonados. A matéria "Importância da adoção consciente de animais abandonados" disponibilizada no site https://blog.finofaro .com.br/importancia-da-adocao-consciente-de-animais-abandonados/; traz vários aspectos importantes da questão.

${ }^{16}$ CRFB/88. "Art. 225: Todos têm direito ao meio ambiente ecologicamente equilibrado, bem de uso comum do povo e essencial à sadia qualidade de vida, impondo-se ao Poder Público e à coletividade o dever de defendê-lo e preservá-lo para as presentes e futuras gerações.

Parágrafo $1^{\circ}$ Para assegurar a efetividade desse direito, incumbe ao Poder Público:

Inciso VII: proteger a fauna e a flora, vedadas, na forma da lei, as práticas que coloquem em risco sua função ecológica, provoquem a extinção de espécies ou submetam os animais à crueldade."
} 
se observa em diversos artigos do Código Civil e práticas tuteladas nesta seara, ou seja, é possível a compra e venda de animais, ações em decorrência de vícios ocultos e redibitórios, eutanásia a pedido do "dono".

No entanto, é possível observar doutrina e jurisprudência indicando uma nova forma de pensar que ultrapassa o pensamento meramente antropocêntrico, e altera a natureza jurídica dos animais para sujeitos de direito. Expressões como propriedade, posse, dono são criticadas e dão lugar a guardião, tutor. Projetos de lei preveem um novo tratamento jurídico em esfera nacional e internacional. No Brasil estão em trâmite o projeto de lei n²8 de 2018 (sujeitos despersonificados) e o projeto ${ }^{\circ} 351$ de 2015 (animais não são coisas) ${ }^{17}$. Portugal, por exemplo, em março de 2017 aprovou a lei ${ }^{18}$ que institui o Estatuto Jurídico dos Animais, alterando o Código Civil e o Código de processo Civil português, reconhecendo a sua natureza de seres vivos dotados de sensibilidade, e Código Civil Francês em 2016 ${ }^{19}$. Há um reconhecimento da sensibilidade animal. Novos projetos e doutrina cada vez mais conferem novo tratamento para os animais. ${ }^{20}$

Caminha-se para o reconhecimento de uma doutrina que confere aos animais a natureza de sujeitos, com reconhecimento de dignidade e senciência. Com início na filosofia, aos poucos ganha espaço na esfera jurídica e na sociedade em um movimento internacional e nacional.

${ }^{17}$ O Projeto de Lei $\mathrm{n}^{\circ} 6.799$ de 2013, atual projeto de lei $\mathrm{n}^{\circ} 28$ de 2018, de autoria do deputado Ricardo Izar, estabelece regime jurídico especial para os animais domésticos e silvestres, entendendo-os como sencientes e detentores de natureza jurídica sui generis, sendo sujeitos de direitos despersonificados, dos quais podem gozar e obter a tutela jurisdicional em caso de violação, sendo vedado o seu tratamento como coisa.

Apesar de aprovado na Câmara dos deputados e senado, foram propostas três emendas ao projeto, portanto, segue a tramitação. As emendas lamentavelmente pretendem excluir justamente os animais que mais necessitam de proteção, ou seja, aqueles utilizados nas chamadas práticas culturais (por exemplo: vaquejada e rodeios), agropecuária (alimentação), experimentação (atividade científica).

O Projeto de Lei do Senado n 351 de 2015, proposto pelo senador Augusto Anastasia, que altera o Código Civil, para determinar que os animais não sejam considerados coisas, mas bens móveis para os efeitos legais, salvo o disposto em lei especial. Animais seriam considerados bem, no sentido de bem imaterial, diferenciando-os de objeto, de bem material coisa.

${ }^{18}$ Portugal, Lei n. ${ }^{\circ} 8 / 2017$.

${ }^{19} \mathrm{O}$ Código Civil Francês foi alterado pelo parlamento francês incluindo e reconhecendo os animais como seres sencientes. Reconhece desta forma que animais possuem sentimentos. Altera seu status jurídico de propriedade (artigo 528) para seres sencientes (novo artigo 514 e 515), sujeitos a serem considerados por si próprios e não por seu valor patrimonial.

Art. 515-14. du Code civil - Les animaux sont des êtres vivants doués de sensibilité. Sous réserve des lois qui les protègent, les animaux sont soumis au régime des biens". Alteração em 0112015.

20 "Nova lei considera animais domésticos como crianças ao invés de propriedades nos EUA. Nos últimos dias de dezembro, o estado norte -americano Illinois aprovou uma nova lei que considera animais como crianças em casos de custódia. A lei, que entrou em vigor em $1^{\circ}$ de Janeiro deste ano é semelhante a uma legislação do Alasca e deixa de considerar animais como propriedades para tratá-los como seres vivos que merecem ter seus melhores interesses atendidos.

Disponível em <https://www.anda.jor.br/2018/02/nova-lei-considera-animais-domesticos-como-criancas-ao-invesde-propriedades-nos-eua/> Acesso em 08.02.2018 
Teorias como as de Descartes comparando o animal a uma máquina (teoria do animal máquina) perdem espaço para filósofos, cientistas e estudiosos que compreendem o bem-estar animal e questionam sua natureza jurídica de coisa. Alteridade, solidariedade, respeito com as demais espécies, defesa de uma nova natureza jurídica como sujeito tornam- se uma preocupação.

Por volta de 1970 o movimento em prol do reconhecimento do direito dos animais ganhou espaço, o termo especismo, com o filósofo Richard Ryder de Oxford, é inserido na enciclopédia britânica, ou seja, a desconsideração por espécies que não sejam a humana, num paralelo ao racismo e especismo.

Livros são lançados com teorias que incluem o animal na esfera de consideração moral, a temática e reflexão sobre os animais ganha espaço. Forma-se uma disciplina autônoma, com reflexos ambientais e para o animal individualmente considerado, cursos de extensão, disciplinas autônomas, pós-graduação, mestrados e doutorados, congressos abordando a questão animal, as crueldades sofridas em suas tristes realidades cotidianas. ${ }^{21}$

Forma-se um novo ramo do direito com preceitos doutrinários nos quais animais possuem titularidade de direitos como vida, liberdade, integridade física e psíquica. Animais como sujeitos de direito, como entes despersonalizados ou como sui generis. Animais com direito a vida digna e um mínimo existencial. Respeito por sua natureza e essência, liberdade para viverem com seus pares em conformidade com suas necessidades inerentes, independente do homem ou para o proveito deste.

Forte doutrina se forma estendendo dignidade para os animais a partir da filosofia, biologia, veterinária e também de estudiosos do Direito. Apesar de minoritário este posicionamento, muitos doutrinadores contemporâneos defendem que os animais são ou devem ser verdadeiros titulares de direito, tais como Daniel Braga Lourenço, Fábio Correa Souza de Oliveira, Heron José Santana Gordilho, Tagore Trajano, Edna Cardoso Dias, Laerte Fernando Levai, Danielle Tetü Rodrigues, Fernanda Medeiros, Rita Paixão, Samylla Mol, Ana Barbuda, Laura Cecília Braz entre outros. Ou que devem estar inseridos na categoria do mínimo existencial, como afirma Fábio C.S.de Oliveira (2008), englobando as condições físicas, valores psíquicos, e, apesar de normalmente apenas o homem estar sendo atingido por estes preceitos, a dignidade, que está sempre acompanhada do mínimo existencial, deve englobar os animais.

\footnotetext{
${ }^{21}$ Exemplos: em 2016 foi inserida na grade de eletivas ou tópicos no curso de Direito da Universidade Veiga de Almeida no Rio de Janeiro. Em 2018 a Facha inicia a primeira pós-graduação em Direito dos Animais no Rio de Janeiro. A UFBA possui linha de pesquisa e disciplina sobre a questão animal no mestrado e doutorado.
} 
Se até então a proteção dos animais advinha principalmente do interesse do homem, seja em decorrência do direito de propriedade ou importância do meio ambiente, hoje, o reconhecimento de que animais são seres sencientes e com capacidades lhes confere proteção em decorrência de sua própria natureza.

Sob estes aspectos, é questionável o procedimento da eutanásia sem considerar o animal propriamente, que controle de zoonoses, exercido pelo Poder Público, ocorra simplesmente com a retirada dos animais de seus lares ou das ruas e mortos, não sendo acompanhada de políticas sociais preventivas e mais humanas, ou experimentos que permitem a morte de animais sadios ou mesmo a simples vontade de seus "tutores".

\section{Critérios e resultados para aplicação da eutanásia.}

Para se estabelecer limites para aplicação da eutanásia em animais, cabe a observância do princípio da utilidade ou maior felicidade, uma vez que deve ser estendido aos animais, conforme Jeremy Bentham, trazidos em sua obra 'Uma Introdução aos Princípios da Moral e da Legislação, ${ }^{22}$, considerando a capacidade de sofrer dos animais.

Outro ponto que deve basilar a questão é o reconhecimento dos animais como sujeitos de direitos e o reconhecimento da senciência animal. De acordo com as teorias filosóficas contemporâneas, não se pode em nome de proteção ambiental e vontade humana ser indiferente ao animal individualmente considerado e simplesmente permitir a eutanásia como forma mais barata e fácil. Neste viés, devem ser destacados os seguintes parâmetros:

1.0 reconhecimento da senciência animal. Em 2012, houve o reconhecimento da existência da senciência, constatando ou reafirmando que animais possuem vontade, medo, estresse, dor, felicidade, conforme Declaração de Cambridge sobre a Consciência em Animais

\footnotetext{
${ }^{22}$ Bentham, 1974, p. 69 (...) Pode vir o dia em que o resto da criação animal adquira aqueles direitos que nunca lhes deveriam ter sido tirados, se não fosse por tirania. Os franceses já descobriram que a cor preta da pele não constitui motivo algum pelo qual um ser humano possa ser entregue, sem recuperação, ao capricho do verdugo. Pode chegar o dia em que se reconhecerá que o número de pernas, a pele peluda, ou a extremidade do os sacrum constituem razões igualmente insuficientes para abandonar um ser sensível à mesma sorte. Que outro fator poderia demarcar a linha divisória que distingue os homens dos outros animais? Seria a faculdade de raciocinar, ou talvez a de falar? Todavia, um cavalo ou um cão adulto é incomparavelmente mais racional e mais social e educado que um bebê de um dia, ou de uma semana, ou mesmo de um mês. Entretanto, suponhamos que o caso fosse outro: mesmo nesta hipótese, que se demonstraria com isso? O problema não consiste em saber se os animais podem raciocinar; tampouco interessa se falam ou não; o verdadeiro problema é este: PODEM ELES SOFRER?". Grifou-se.
} 
Humanos e Não Humanos (The Cambridge Declaration of Consciousness), datada de 7 de julho de 2012, em Cambridge, Reino Unido, na Francis Crick Memorial Conference on Consciousness in Human and non-Human Animals, no Churchill College, da Universidade de Cambridge firmada por cientistas de instituições como a Universidade de Stanford, o Massachusetts Institute of Technology (MIT) e o Instituto Max Planck, redigido por Philip Low, em evento que contou com a presença de Stephen Hawking; e editado por Jaak Panksepp, Diana Reiss, David Edelman, BrunoVan Swinderen, Philip Low e Christof Koch.

Este reconhecimento pela ciência é um destaque, ou seja, capacidade de sensações e sentimentos, e, em grau mais desenvolvido da autoconsciência, isto é, consciência de si próprio, de transmitir conhecimento e cultura, que torna obrigatório o reconhecimento de animais como sujeitos e a necessidade de novos preceitos na legislação e em procedimentos como eutanásia. Traz à baila o questionamento moral quanto à desconsideração da vida animal, pois há o reconhecimento de sua existência, constatação de que possuem vontade, medo, estresse, dor, felicidade.

2. Combate ao especismo, pois a simples realização da eutanásia reforça essa ideia ao desconsiderar as demais espécies e afastar o princípio da alteridade quanto aos animais. Teorias como as de Tom Regan (animais como sujeitos de uma vida - consciência existencial), Peter Singer (igual consideração de interesses para os seres envolvidos), ou Gary Lawrence Francione (animais não são propriedade) devem ser refletidas.

3. Ampliação do direito à vida, ao respeito e à dignidade para todos os seres vivos, seja ele animal humano ou não humano, a alteridade é princípio que deve ser estendido a todas as espécies.

Alteridade, o olhar para o outro, para o rosto do outro que vive, sofre e morre permite a consideração e responsabilidade por este rosto, que possui uma individualidade e deve ser considerado, é preciso estabelecer o bem para além do ser, considerar o outro. Conforme Lévinas (2010), é preciso considerar o ser vivente, seu modo de ser e buscar viver a vida, portanto, a indiferença é o ponto que deve ser rompido, para então considerar a vida do outro.

Assim, a vulnerabilidade do outro, animal, a alteridade deve ser considerada, Lévinas destaca que a existência em sofrimento, abandono, solidão e incapacidade para superar esta dor deve despertar empatia. A dor é o mal por si só: “Ao sofrimento refere-se todo mal. Ele é o impasse da vida e do ser, seu absurdo em que a dor não vem "colorir" de afetividade, e de certa 
maneira inocente, a consciência. O mal da dor, o próprio dano, é o esfacelamento e como que a articulação mais profunda do absurdo" (LÉVINAS, 2010, p.119).

\section{Resultados:}

A análise do procedimento chamado eutanásia em animais demonstra que são poucos os casos de realização em interesse do animal, ou seja, para proporcionar fim do sofrimento e morte digna. Percebe-se uma regulamentação que possibilita procedimento de morte com intuito de proteção ambiental e humano, ou mesmo, sem qualquer justificativa, ou seja, por mera vontade do tutor.

As formas de eutanásia regulamentada nas resoluções do CFMV, CONAMA e CONCEA nem sempre são seguras quanto a ausência de dor e sofrimento.

Tabela 1. Distribuição quantitativa do tipo de animais utilizados por tipologia e ano

\begin{tabular}{|l|l|l|l|l|l|}
\hline ANO & TOTAL POR ANO & $\begin{array}{l}\text { ANIMAIS } \\
\text { LABORATÓRIO }\end{array}$ & $\begin{array}{l}\text { ANIMAIS } \\
\text { SILVESTRES }\end{array}$ & $\begin{array}{l}\text { ANIMAIS } \\
\text { DOMÉSTICOS }\end{array}$ & $\begin{array}{l}\text { ANIMAIS } \\
\text { PRODUÇÃO }\end{array}$ \\
\hline 2003 & 1.932 & 1.560 & 238 & 110 & 24 \\
\hline 2004 & 1.701 & 1.246 & 124 & 180 & 151 \\
\hline 2005 & 2.856 & 2.461 & 76 & 101 & 218 \\
\hline 2006 & 3.522 & 2.858 & 311 & 130 & 223 \\
\hline 2007 & 1.836 & 636 & 349 & 73 \\
\hline 2008 & 1.933 & 532 & 202 & 127 \\
\hline 2009 & 3.460 & 548 & 660 & 447 \\
\hline 2010 & 2.794 & 492 & 605 & 400 \\
\hline & 5.115 & 17.715 & 2.957 & & 2.337 \\
\hline TOTAL GERAL & 24.672 & $71,8 \%$ & $11,98 \%$ & $9,47 \%$ & 1.663 \\
\hline PERCENTUAL & $100 \%$ & & & $6,74 \%$ \\
\hline
\end{tabular}

A tabela demonstra pesquisa realizada e publicada na revista Bioética em 2017 e indica, por meio da análise de 390 protocolos examinados ao longo de 8 anos, o número elevado de animais submetidos a "eutanásia" e questiona o procedimento. (REVISTA BIOÉTICA. Disponível em http://revistabioetica.cfm.org.br/index. php/revista_bioetica/article/view/1268/1779).

\section{Conclusão:}

Através da pesquisa é possível perceber que a expressão eutanásia realizada em animais nem sempre aplica seu real significado de "boa morte", pois trata-se de forma comum de controle de zoonoses, de interesse humano e após experimentação científica, ainda que os animais estejam sadios.

Os órgãos que regulamentam o procedimento preveem princípios éticos (senciência e o animal), mas priorizam os interesses humanos e questões de ordem econômica, já que a "eutanásia" pode significar uma forma mais barata de solucionar o "problema".

Direito dos Animais, princípios da bioética devem ser estendidos aos animais, sendo estes os sujeitos\pacientes a serem considerados. 
Diversas doenças ou zoonoses são tratáveis, sendo injustificado o procedimento da eutanásia. Animais sadios não devem ser sacrificados e o veterinário não deve realizar a “eutanásia" por simples vontade do responsável, tendo destacado papel no esclarecimento dos responsáveis pelos animais sobre os critérios específicos para a prática da eutanásia, bem como do dever de tratamento dos animais sob sua responsabilidade.

Importante observar que critérios econômicos das famílias ou governo não justificam o procedimento da eutanásia ou ser motivo para se deixar de conferir dignidade e cuidados com os animais.

O governo deve intervir de forma a tutelar os animais, para garantia do bem estar, felicidade, evitando danos e sofrimento aos animais, bem como não admitindo que os animais sejam descartados como coisas, em razão de enfermidade, pois, na maioria dos casos, existe possibilidade de tratamento, sendo a eutanásia possível apenas em último caso e na hipótese de agonia do animal, constatando-se seu interesse.

A sociedade, o governo e as entidades de proteção devem buscar a conscientização através de ações e questionamentos morais que provoquem uma mudança de visão quanto aos animais, especialmente no âmbito da responsabilidade civil dos seus donos.

\section{Referências Bibliográficas}

ASUA, Luis Jiménez de. Libertad de amar y derecho a morir: ensayos de un criminalista sobre eugenesia y eutanasia. Buenos Aires: Depalma, 1992

BENTHAM, Jeremy. Uma Introdução aos princípios da moral e da legislação. São Paulo: Abril Cultural, 1974. (Os Pensadores).

CARRILHO JORGE, Leonardo. Paternalismo Jurídico na Constituição de 1988: a autonomia individual contra o autoritarismo estatal. Dissertação de mestrado em Direito Público. UERJ.

CHALFUN, Mery; OLIVEIRA, Fábio. Experimentação Animal: Por um tratamento ético e pelo Biodireito. In: Marcelo Campos Galuppo. (Org.). Encontro Nacional do CONPEDI (18: 2009: Maringá, PR). 1ª ed. Florianópolis: Centro Universitário de Maringá e Fundação Boiteux, 2009, v. 1, p. $1228-1257$.

CORREA NETO, Josué Lopes.; LORENZO, Cláudio; SANCHEZ, Mauro Niskier. Influência de uma comissão de ética na proteção de animais. Disponível em http://www.scielo.br/pdf/bioet/v25n3/1983-8042-bioet-25-03-0630.pdf. 2017 
DINIZ, Maria Helena. O Estado Atual do Biodireito. 9 ed. São Paulo.: Saraiva, 2014.

FELIPE, Sônia T. Ética e experimentação animal: fundamentos abolicionistas. Florianópolis: EDUFSC, 2007.

Guia Brasileiro de Boas Práticas em Eutanásia em Animais - Conceitos e Procedimentos Recomendados - Brasília, 2012 1v.

LÉVINAS, Emmanuel. Entre Nós: Ensaios sobre a alteridade. Tradução de Pergentino Pivatto. 5.ed. Petrópolis, RJ: Vozes, 2010.

LOURENÇO, Daniel Braga. Direito dos Animais: Fundamentação e Novas Perspectivas. Porto Alegre: Sergio Antonio Fabris, 2008.

MACHADO, Carlos José Saldanha; SILVA, Erica Gaspar e VILANI, Rodrigo Machado. O uso de um instrumento de política de saúde pública controverso: a eutanásia de cães contaminados por leishmaniose no Brasil. Saude soc. [online]. 2016, vol.25, n.1, pp.247-258. ISSN 0104-1290. http://dx.doi.org/10.1590/S0104-12902016146918.

MALUF, Adriana Caldas do Rego Freitas Dabus. Curso de Bioética e Biodireito. São Paulo: Atlas, 2013.

OLIVEIRA, Fábio Correa Souza. Categorias dos direitos humanos aplicadas aos direitos dos animais não-humanos: Do caminho em curso ao caminho a percorrer. In: I CONGRESSO MUNDIAL DE BIOÉTICA E DIREITO DOS ANIMAIS. Salvador, outubro, 2008

PAIXÃO, Rita Leal. Experimentação animal: razões e emoções para uma ética. Tese de Doutorado. Fundação Oswaldo Cruz. Escola Nacional de Saúde Pública, 2001.

PESSINI, Leocir. Eutanásia: Por que abreviar a vida? São Paulo: Loyola, 2004.

REGAN, Tom. Jaulas Vazias. Porto Alegre: Lugano, 2006.

RON, Leifer. Projeto Felicidade. São Paulo: Editora Cultrix Ltda, 1997.

SANDEL, Michael. O que o dinheiro não compra: os limites morais do mercado. Rio de Janeiro: Civilização Brasileira, 2012.

SARLET, Ingo Wolfgang Sarlet; FENSTERSEIFER, Tiago. Algumas notas sobre a dimensão ecológica da dignidade da pessoa humana e sobre a dignidade da vida em geral. In: MOLINARO; MEDEIROS; SARLET; FENSTERSEIFER (Org.) A dignidade da vida e os direitos fundamentais para além dos humanos: uma discussão necessária. Belo Horizonte: Fórum, 2008. 
SILVA, Lívia Maria de Moura. A ilegalidade da "eutanásia animal” em face dos princípios que regem o direito administrativo. Disponível em: http://www.abolicionismoanimal.org.br/artigos/ailegalidadedaeutansiaanimalemfacedosprincpios queregemodireitoadministrativo.pdf

SILVA, Tagore Trajano de Almeida. A lei Arouca: Ainda continuamos a realizar pesquisas com animais. Disponível em Revista de Direito Animal on line Pensata Animal $<$ http://www.pensataanimal.net/index.php?option=com_content\&view=articl\&id=56:promotoria -de-defesa-animal\&catid=46:laerteleavi\&itemid=1>

SINGER, Peter. Libertação Animal. Porto Alegre: Lugano, 2004.

SOTO, Francisco Rafael Martins. Eutanásia Canina nos Centros de Controle de Zoonoses. Arq. Ciênc. Vet. Zool. UNIPAR, Umuarama, v. 13, n. 1, p. 43-46, jan./jun. 2010. Disponível em file:///C:/Users/Carlos\%20Roberto/Downloads/3376-10977-1-PB\%20(1).pdf

SUETÔNIO. A vida dos doze Césares. Tradução de Sady-Garibaldi. 2. ed. São Paulo: Prestígio Ed, 2002.

TRÉZ, Thales. Experimentação Científica: Um Obstáculo ao Avanço Científico. Porto Alegre: Tomo Editorial, 2015.

Sites:

Concea reconhece 17 métodos alternativos ao uso de animais. Fonte: Ministério da Ciência, Tecnologia e Inovação. Publicado por Portal Brasil, em 03 set 2014. Disponível em: $<$ http://www.brasil.gov.br/ciencia-e-tecnologia/2014/09/concea-reconhece-17-metodosalternativos-ao-uso-de-animais> acesso em: 28 ago 2016.

CNPQ recebe propostas de métodos alternativos para o uso de animais em pesquisas. Fonte: Agência Brasil e Anvisa. Publicado por Portal Brasil, em 15 out 2012. Disponível em: <http://www.brasil.gov.br/ciencia-e-tecnologia/2012/10/cnpq-recebe-propostas-de-metodosalternativos-para-o-uso-de-animais-em-pesquisas>

Guia Brasileiro de Produção, Manutenção ou Utilização de Animais em Atividades de Ensino ou Pesquisa Científica. Coordenador: Bruno Lourenço Diaz - Universidade Federal do Rio de Janeiro. Fascículo 6, $1^{\text {a }}$ Edição. Brasília, 31 mar 2016. Disponível em: <http://www.mct.gov.br/upd_blob/0239/239139.pdf> 
file://C:/Users/Carlos\%20Roberto/Downloads/3376-10977-1-PB.pdf

https://noticias.uol.com.br/internacional/ultimas-noticias/the-new-york-

times/2012/08/06/zoologicos-adotam-metodo-de-eutanasia-para-controlar-crescimento-deespecies.htm

https://www.anda.jor.br/2010/05/veterinarios-esclarecem-as-situacoes-em-que-a-eutanasia-eindicada/

http://www.mctic.gov.br/mctic/export/sites/institucional/institucional/concea/arquivos/legislacao /resolucoes_normativas/Resolucao-Normativa-CONCEA-n-13-de-20.09.2013-D.O.U.-de26.09.2012-Secao-I-Pag.-5.pdf 